\title{
Decreto para protección de no fumadores en la Ciudad de México
}

DECRETO POR EL QUE SE REFORMAN, ADICIONAN Y DEROGAN LA LEY DE PROTECCIÓN A LA SALUD DE LOS NO FUMADORES DEL DISTRITO FEDERAL Y LA LEY PARA EL FUNCIONAMIENTO DE ESTABLECIMIENTOS MERCANTILES DEL DISTRITO FEDERAL .

(Al margen superior un escudo que dice: Ciudad de México.- Capital en Movimiento).

DECRETO POR EL QUE SE REFORMAN, ADICIONAN Y DEROGAN LA LEY DE PROTECCIÓN A LA SALUD DE LOS NO FUMADORES DEL DISTRITO FEDERAL Y LA LEY PARA EL FUNCIONAMIENTO DE ESTABLECIMIENTOS MERCANTILES DEL DISTRITO FEDERAL.

MARCELO LUIS EBRARD CASAUBON, Jefe de Gobierno del Distrito Federal a sus habitantes sabed:

Que la H. Asamblea Legislativa del Distrito Federal, IV Legislatura se ha servido dirigirme el siguiente:

\section{Decreto}

(Al margen superior un sello con el Escudo Nacional que dice: ESTADOS UNIDOS MEXICANOS.- ASAMBLEA LEGISLATIVA DEL DISTRITO FEDERAL IV LEGISLATURA)

ASAMBLEA LEGISLATIVA DEL DISTRITO FEDERAL IV LEGISLATURA.

DECRETA

DECRETO POR EL QUE SE REFORMAN, ADICIONAN Y DEROGAN LA LEY DE PROTECCIÓN A LA SALUD DE LOS NO FUMADORES DEL DISTRITO
FEDERAL Y LA LEY PARA EL FUNCIONAMIENTO DE ESTABLECIMIENTOS MERCANTILES DEL DISTRITO FEDERAL.

PRIMERO. Se REFORMAN las fracciones I y III del artículo 1 Bis; la fracción III del artículo $3^{\circ}$; el artículo $4^{\circ}$; la fracciones VIII y IX del artículo $5^{\circ}$; el primer párrafo y las fracciones I, II, III Y V del artículo $6^{\circ}$; la fracción V del artículo $7^{\circ}$; el segundo párrafo de la fracción 11 y el último párrafo del artículo $8^{\circ}$; el primer párrafo del artículo 9 Ter; las fracciones I, II, V, X , XIII Y el penúltimo párrafo del artículo $10^{\circ}$; el artículo 13; el párrafo primero del artículo 14; el primer párrafo del artículo 15; el primer y segundo párrafos del artículo 16; el primer párrafo del artículo 21; el artículo 27, el primer párrafo del artículo 28; la fracción I del artículo 29; el artículo 30; el artículo 31; y el artículo 32; se ADICIONAN un segundo párrafo al artículo $9 \mathrm{Bis}$, las fracciones $\mathrm{X}$ Bis y $X$ Ter al artículo $10^{\circ}$; un segundo párrafo, las fracciones I, II, III, IV YV, un penúltimo y último párrafo al artículo 15; y se DEROGAN el segundo párrafo de la fracción I del artículo $6^{\circ}$; el último párrafo del artículo $10^{\circ}$; el artículo 11; el artículo 12 Bis; las fracciones I, II, III, el penúltimo y último párrafos del artículo 14; las fracciones I, II Y III del artículo 20; y el artículo 21; todos de la Ley de Protección a la Salud de los No Fumadores del Distrito Federal, para quedar como sigue:

Artículo 1 Bis.- ...

I. El derecho de las personas no fumadoras a no estar expuestas al humo del tabaco en los espacios cerrados de acceso público;

II ....

III. La prohibición de fumar en los espacios cerrados públicos, privados y sociales que se señalan en esta ley;

IV. a V .... 
Artículo 3.- ...

I. a II. ...

III. Los usuarios de los espacios cerrados de acceso al público como oficinas, establecimientos mercantiles, industrias y empresas, que en todo momento podrán exigir el cumplimiento de las disposiciones de la presente Ley;

IV. a $\mathrm{V}$....

Artículo 4.- En el procedimiento de verificación, impugnaciones y sanciones a las que se refiere la presente Ley será aplicable la Ley de Procedimiento Administrativo del Distrito Federal y el Reglamento de Verificación Administrativa para el Distrito Federal.

Artículo 5.- ...

I. a VII ...

VIII.Espacio cerrado de acceso al público: Es todo aquel en el que hacia su interior no circula de manera libre el aire natural. Las ventanas, puertas, ventilas y demás orificios o perforaciones en delimitaciones fisicas no se considerarán espacios para la circulación libre de aire natural;

IX. Publicidad del tabaco: Es toda forma de comunicación, recomendación o acción comercial con el fin o el efecto de promover directa o indirectamente un producto de tabaco o el uso o consumo del mismo;

X. a XII. ...

Artículo 6.- El Gobierno del Distrito Federal, a través de las instancias administrativas correspondientes, en sus respectivos ámbitos de competencia, ejercerán las funciones de vigilancia, inspección y aplicación de sanciones que correspondan en el ámbito de su competencia, para lo cual tendrá las siguientes atribuciones:

I. Conocer de las denuncias presentadas por los ciudadanos o usuarios, cuando no se respete la prohibición de fumar, en los términos establecidos en la presente Ley;

II. Ordenar de oficio o por denuncia ciudadana, la realización de visitas de verificación en los establecimientos mercantiles, oficinas, industrias y empresas, así como en las instalaciones de los Órganos de Gobierno del Distrito Federal y de los Órganos Autónomos del Distrito Federal, para cerciorarse del cumplimiento de las disposiciones de esta Ley;

III. Sancionar según su ámbito de competencia a los propietarios o titulares de los establecimientos mercantiles, oficinas, industrias y empresas que no cumplan con las disposiciones de esta Ley;
IV. ....

V. Informar a los órganos de control interno de las oficinas o instalaciones que pertenezcan a los Órganos de Gobierno del Distrito Federal o a los Órganos Autónomos del Distrito Federal, la violación a la Ley Federal, en razón de su jurisdicción, de los servidores públicos, a efecto de que se inicien los procedimientos administrativos correspondientes; $\mathrm{y}$

VI. ...

\section{Artículo 7.- ...}

I a IV ....

V. Diseñar el manual de letreros y/o señalamientos preventivos, informativos o restrictivos, que serán colocados al interior de los establecimientos mercantiles, oficinas, industrias y empresas, así como en las oficinas de los Órganos de Gobierno del Distrito Federal y de los Órganos Autónomos del Distrito Federal, para prevenir el consumo de tabaco y establecer las prohibiciones pertinentes, mismos que deberán contener iconografia relativa a los riesgos y consecuencias del tabaquismo;

Artículo 8.- ....

I. ...

II ....

Para el caso de establecimientos mercantiles, oficina, industria o empresa, Seguridad Pública procederá a petición del titular o encargado de dichos lugares; $\mathrm{y}$

III ....

Las atribuciones a que se refiere este artículo serán ejercidas por Seguridad Pública, a través de la policía del Distrito Federal, quienes al momento de ser informados de la comisión de una infracción, por el titular, encargado o responsable del establecimiento mercantil, oficina, industria, empresa o de la instalación del Gobierno del Distrito Federal o de sus Órganos Autónomos que corresponda, invitarán al infractor a modificar su conducta, a trasladarse a las áreas donde se puede fumar, en el caso de que existan, o a abandonar el lugar y en caso de no acatar la indicación, pondrán a disposición del Juez Cívico que se trate, al infractor.

Artículo 9 Bis.- ...

El programa contra el tabaquismo incluirá acciones tendientes a prevenir, tratar, investigar e informar sobre los daños que producen a la salud el consumo de tabaco y el humo del tabaco. 
Artículo 9 Ter.- La prevención del tabaquismo tiene carácter prioritario, haciendo énfasis en la infancia y la adolescencia, con enfoque de género, y comprenderá las siguientes acciones:

I a VII ...

Artículo 10.- ...

I. En todos los espacios cerrados de acceso al público, oficinas, establecimientos mercantiles, industrias y empresas;

II. En elevadores y escaleras interiores de cualquier edificación;

III. a IV ....

V. En hospitales, clínicas, centros de salud, consultorios, centros de atención médica públicos, sociales o privados, salas de espera, auditorios, bibliotecas, escuelas y cualquier otro lugar cerrado de las instituciones médicas y de enseñanza;

VI. a IX ....

X. En los cines, teatros, auditorios y todos los espacios cerrados en donde se presenten espectáculos de acceso público;

X Bis.- En los establecimientos mercantiles dedicados al hospedaje, de conformidad a lo dispuesto en el articulo 15 de esta Ley;

$X$ Ter.- En los establecimientos mercantiles y espacios cerrados donde se expendan al público alimentos y bebidas para su consumo en el lugar;

XI. a XII. ...

XIII.En espacios cerrados de trabajo y en sitios de concurrencia colectiva; y

XIV.....

Los propietarios, poseedores o responsables de los establecimientos mercantiles, oficinas, industrias y empresas en los cuales está prohibido fumar serán sancionados económicamente por permitir, tolerar o autorizar que se fume.

Artículo 11.- Derogado.

Artículo 12 bis.- Derogado.

Artículo 13.- Es obligación de los propietarios, encargados o responsables de los establecimientos mercantiles en los que se expendan al público alimentos o bebidas para su consumo en el lugar, respetar la prohibición de no fumar en los mismos.

Los usuarios de tales lugares están obligados a observar lo establecido en el párrafo anterior.

Artículo 14.- En los edificios, establecimientos mercantiles, médicos, industriales, de enseñanza e instalaciones de los Órganos de Gobierno del Distrito Federal y Órganos Autónomos del Distrito Federal, que cuenten con áreas de servicio al aire libre se podrá fumar sin restricción alguna, siempre y cuando el humo derivado del tabaco no invada los espacios cerrados de acceso al público.

Artículo 15.- En los establecimientos dedicados al hospedaje, se destinará para las personas fumadoras un porcentaje de habitaciones que no podrá ser mayor al 25 por ciento del total de las mismas.

Las habitaciones para fumadores y no fumadores, deberán estar identificadas permanentemente con señalamiento $\mathrm{s}$ y avisos en lugares visibles al público asistente, dichos señalarnientos y avisos deberán apegarse a los criterios que para el efecto emita la Secretaría de Salud, así como contar con las condiciones mínimas siguientes:

I. Estar aislada fisicamente de las áreas de no fumadores;

II. Tener un sistema de extracción y purificación hacia el exterior;

III. Ubicarse, de acuerdo con la distribución de las personas que ahí concurran, por piso, área o edificio;

IV. Realizar una difusión permanente sobre los riesgos y enfermedades que son causadas por el consumo de tabaco, de conformidad con lo que al efecto determine la Secretaría de Salud, y

V. Sin acceso a ellas con menores de edad.

Las secciones para fumadores a que se refiere el presente artículo no podrán utilizarse como un sitio de recreación.

En el caso de que por cualquier circunstancia no sea posible cumplir con los preceptos a que se refiere el presente artículo, la prohibición de fumar será aplicable al total del inmueble, local o establecimiento.

Artículo 16.- Los propietarios, poseedores o responsables de los establecimientos mercantiles, oficinas, industrias o empresas de que se trate, serán responsables en forma subsidiaria con el infractor, si existiera alguna persona fumando fuera de las áreas destinadas para ello.

El propietario o titular del establecimiento mercantil, oficina, industria o empresa, o su personal, deberá exhortar, a quien se encuentre fumando, a que se abstenga de hacerlo; en caso de negativa se le invitará a abandonar las instalaciones; si el infractor se resiste a dar cumplimiento al exhorto, el titular o sus dependientes solicitarán el auxilio de algún policía, a efecto de que ponga al inftactor a disposición del juez cívico competente.

Artículo 20.- En los locales cerrados y establecimientos en los que se expenden alimentos y bebidas para su consumo en el lugar, los propietarios, poseedores o res- 
ponsables de la negociación deberán colocar dentro de los mismos en lugares visibles letreros y señalamientos relativos a la prohibición de fumar.

Artículo 21.- Derogado.

Artículo 27.- La contravención a las disposiciones de la presente Ley, será considerada falta administrativa, y dará lugar a la imposición de una multa, y en caso de existir reincidencia un arresto por 36 horas.

Artículo 28.- Para la fijación de la multa, que deberá hacerse entre el mínimo y máximo establecido, se tomará en cuenta la gravedad de la infracción concreta, las condiciones económicas de la persona física o moral a la que se sanciona, la reincidencia y demás circunstancias que sirvan para individualizar la sanción.

I a IV ....

Artículo 29.-

I. Multa;

II. a IV ....

Artículo 30.-Se sancionará con multa equivalente de diez a treinta días de salario minimo diario general vigente, a las personas que fumen en los lugares que prohibe el presente ordenamiento; la multa será impuesta por el Juez Cívico correspondiente, y será puesto a disposición de éste, por cualquier policía del Distrito Federal.

Artículo 31.- A los propietarios, poseedores o responsables de los establecimientos mercantiles que no cumplan con las disposiciones de la presente Ley, serán sancionados conforme a las disposiciones de la Ley para el Funcionamiento de Establecimientos Mercantiles del Distrito Federal.

Artículo 32.- Se sancionará con multa equivalente de treinta a cien días de salario minimo diario general vigente al titular de la concesión o permiso cuando se trate de vehículos de transporte público de pasajeros; en el caso de que no fijen las señalizaciones a que se refiere esta Ley, o toleren o permitan la realización de conductas prohibidas por esta Ley.

En los casos de reincidencia en el periodo de un año, se aplicará hasta el doble de la sanción originalmente impuesta; en caso de segunda reincidencia, procederá la revocación de la concesión o permiso.

SEGUNDO. Se REFORMAN las fracciones XXVIy XXVII del artículo $9^{\circ}$; la fracción I del artículo $10^{\circ}$; el segundo párrafo del artículo 11; la fracción IV del artículo 25; el artículo 74; la fracción XV del artículo 77; Se ADICIONA el artículo 3 Bis y se DEROGAN las fracciones $X$ Bis y $X$ Ter del artículo $2^{\circ}$; las fracciones XXVI y XXVII del artículo $9^{\circ}$; todos de la Ley para el Funcionamiento de Establecimientos Mercantiles del Distrito Federal, para quedar como sigue:
Artículo 2.- ...

I. a X ....

X. Bis. Derogado.

X. Ter. Derogado.

XI. a XXV ....

Artículo 3 Bis.- Queda prohibido fumar en todos los establecimientos mercantiles que se encuentren sujetos al cumplimiento de las disposiciones de la presente Ley.

En los establecimientos mercantiles que cuenten con áreas de servicio al aire libre se podrá fumar sin restricción alguna, siempre y cuando el humo derivado del tabaco no invada los espacios cerrados de acceso al público.

Artículo 9.- ...

I. a XXV ....

XXVI. Exhortar a quien se encuentre fumando en el establecimiento, a que se abstenga hacerlo; en caso de negativa, exhortarlo a que abandone el establecimiento; y ante una segunda negativa, solicitar el auxilio de la policía.

XXVII. Señalar clara y permanentemente con avisos en lugares visibles al público asistente la prohibición de fumar en el establecimiento mercantil, así como las sanciones aplicables al infractor.

XXVIII. Derogado.

XXIX ....

Artículo 10.- ...

I. La venta de cualquier tipo de bebidas alcohólicas y productos derivados del tabaco a los menores de edad, aún cuando consuman alimentos;

II. a XVI....

Artículo 11.- ...

En la vía pública en donde se coloquen enseres, se podrá fumar siempre que no sea paso forzoso para las personas; que el humo del tabaco no penetre al interior del establecimiento; y que no se genere un lugar cerrado por instalar barreras que impidan la circulación del aire, cualquiera que fuere el material con las que se elaboren, aunque sean desmontables.

Artículo 25.- ...

I. a III....

IV. Ubicación y superficie total del local donde pretende establecerse el giro mercantil;

V. a X ....

Artículo 74.- Se sancionará con el equivalente de 126 a 350 días de salario mínimo general vigente en el Distrito Federal, el incumplimiento de las obligaciones contempladas o el incurrir en las prohibiciones que 
señalan los artículos 9 fracciones II, III, VIII, XI, XII, XIV, XV, XVI primer párrafo, XIX, XX, XXI Y XXVII; 10 fracciones IV, VI, VII Y XIII; 12; 21 segundo párrafo; 22; 23 último párrafo; 35 fracciones IV y V; 40 segundo párrafo; 42 fracciones II y IV; 46 fracciones I, IV y V; 50; 54; 55 fracción V; 58; 59 fracciones I, II Y V; 60; 62; 65 fracciones II, III, VI y VII, 67; de la Ley.

Artículo 75.- Se sancionará con el equivalente de 351 a 2500 días de salario mínimo general vigente en el Distrito Federal, el incumplimiento de las obligaciones contempladas o el incurrir en las prohibiciones que señalan los artículos 9 fracciones I, V, VI, VII, IX, X, XVI segundo párrafo y XXVI; 10 fracciones I, III, V, VIII, IX, X, XI y XV; $15 ; 16 ; 32 ; 33 ; 34$ tercer y cuarto párrafos; $37,4344,52,55$ fracciones I, II, III Y IV; $57 ; 59$ fracciones III y IV; 61; 65 fracción 1, 67-bis fracciones I, II Y III de la Ley.

Artículo 77.- ...

I. a XIV

XV. Cuando se pennita fumar dentro de los Establecimientos Mercantiles. En este caso, la clausura sólo procederá cuando exista reincidencia. Se entiende que hay reincidencia cuando el Titular del Establecimiento Mercantil haya sido sancionado en más de dos ocasiones durante el transcurso de un año. XVI....

\section{Transitorios}

PRIMERO.- Publíquese en el Gaceta Oficial del Distrito Federal y para su mayor difusión en el Diario Oficial de la Federación.

SEGUNDO.- El presente Decreto entrará en vigor a los treinta días siguientes a los de su publicación en la Gaceta Oficial del Distrito Federal.

TERCERO.- Se deroga el Artículo Cuarto Transitorio del Decreto por el que se reforma y adiciona la Ley para el Funcionamiento de Establecimientos Mercantiles del Distrito Federal y se reforma la Ley de Protección a la Salud de los No Fumadores del Distrito Federal, publicado en la Gaceta Oficial del Distrito Federal el 11 de enero del 2008.

CUARTO.- La Asamblea Legislativa del Distrito Federal y el Gobierno del Distrito Federal implementarán una campaña permanente para dar a conocer los derechos y obligaciones que se derivan por la entrada en vigor del presente Decreto. En dicha campaña no podrán emplearse colores partidistas y se pondrá énfasis para que los adultos no fumen dentro de un vehículo cuando vaya un menor adentro.

Recinto de la Asamblea Legislativa del Distrito Federal, a los veintiséis dias del mes de febrero del año dos mil ocho. POR LA MESA DIRECTIV A.- DIP. JORGE FEDERICO SCIIIAFFINO ISUNZA, PRESIDENTE.- DIP. DANIEL SALAZAR NUÑEZ, SECRETARIO.- DIP. MARGARITA MARÍA MARTÍNEZ FISHER.- SECRETARIA.- Firmas.

En cumplimiento de lo dispuesto por los artículos 122, apartado C, Base Segunda, fracción II, inciso b), de la Constitución Política de los Estados Unidos Mexicanos; 48, 49 Y 67 fracción II, del Estatuto de Gobierno del Distrito Federal, y para su debida publicación y observancia, expido el presente Decreto Promulgatorio, en la Residencia Oficial del Jefe de Gobierno del Distrito Federal, en la Ciudad de México, a los veintiocho días del mes de febrero de dos mil ocho. EL JEFE DE GOBIERNO DEL DISTRITO FEDERAL, MARCELO LUIS EBRARD CASAUBON.-FIRMA.- EL SECRETARIO DE GOBIERNO, JOSÉ ÁNGELÁ VILA PÉREZ.- FIRMA.- EL SECRETARIO DE SALUD, MANUEL MONDRAGÓN $Y$ KALB.-FIRMA. 